\title{
Effect of Consumer Demographics and Risk Factors on Online Purchase Behaviour in Malaysia
}

\author{
Noorshella Che Nawi ${ }^{1}$, Abdullah Al Mamun ${ }^{2, *} \mathbb{D}$, Nurul Hasliana Binti Hamsani ${ }^{1}$ and \\ Mohd Nazri bin Muhayiddin ${ }^{1}$ (D) \\ 1 Faculty of Entrepreneurship and Business, Universiti Malaysia Kelantan, Kota Bharu 16100, Malaysia; \\ norshella@umk.edu.my (N.C.N.); hasliana.h@umk.edu.my (N.H.B.H.); mnazri@umk.edu.my (M.N.b.M.) \\ 2 Global Entrepreneurship Research and Innovation Centre (GERIC), Universiti Malaysia Kelantan, \\ Kota Bharu 16100, Malaysia \\ * Correspondence: abdullah.a@umk.edu.my or mamun7793@gmail.com; Tel.: +6-0133003630
}

Received: 4 December 2018; Accepted: 22 January 2019; Published: 24 January 2019

\begin{abstract}
It is evident that there has been a rapid growth of electronic commerce and online shopping. Hence, this study examined the effect of selected antecedents and risk factors on online purchase behaviour in Malaysia under the premise of an adapted stimulus-organism-response (SOR) model. This study used a cross-sectional design to collect data from 330 selected respondents from Peninsular Malaysia. The findings revealed that the age of consumers, as well as perceived after-sales risk, financial risk, psychological risk, and social risk, had a significant effect on the online purchase behaviour in Malaysia. Apart from enriching the existing body of knowledge, this study offers several significant practical implications. Based on the findings, it is recommended that the government and online businesses should focus on Generation Y, who are known to be more tech-savvy, through policies and programmes in order to reduce the various types of perceived risks associated with online transactions. It is believed that this effort could enhance online consumerism among the residents of Malaysia.
\end{abstract}

Keywords: antecedents; risk factors; online purchase behaviour

\section{Introduction}

The growing use of information technology and the Internet, as well as the potential to provide easy and speedy consumer access to the diverse products directly from their sellers over the Internet, 24-hours-a-day, seven-days-a-week, regardless of their geographical location, has significantly contributed towards the popularity of online shopping as a form of electronic commerce [1-4]. Moreover, online businesses can potentially obtain promising sales as a result of the unique economic feature of reaching vast consumers in a short period at a lower cost [2,3,5]. In Malaysia, online shopping has grown in every dimension and the recorded online retail transactions in 2011 were worth RM1.8 billion (70\% more than the previous year), and are expected to reach RM22.6 billion by 2020 [3].

Due to the intense and competitive nature of e-commerce markets, it is important to enhance the probability of website visits that could transform into purchases (purchasing behaviour) for the success of online business [5]. The advancements of the Internet have changed online purchase behaviour as a result of the changing dynamics that surround it [6]. According to Rahman and Mannan [7], online purchase behaviour can be developed through the innovative use of Web technologies and online brand familiarity, which are currently growing at a rapid pace and eclipsing traditional buying processes. This phenomenon has caused the rapid market entry of numerous online sellers. The development of e-commerce has influenced online purchasing behaviour and this phenomenon 
has been highlighted in different studies including economic management, data mining, marketing, and forecasting [5].

Internet shopping has become prevalent and it provides large reservoirs of market potential for e-commerce [2], which calls for further investigation into the subject matter. There has been a relatively constant growth of customers' preferences towards online shopping [7] among many emerging economies, such as Malaysia [2]. Although a few previous studies have provided significant insights regarding the complexities of online markets, the existing literature on online purchasing behaviour is inadequate, particularly in the Malaysian context (see [2,5]). It is believed that the inadequate body of knowledge on online purchasing behaviour discouraged the local online businesses in Malaysia, which led to the withdrawal of Malaysia from the Top 30 Global Retail E-Commerce rankings in 2015, despite the flourishing e-commerce growth globally [2]. Thus, this study examined the effects of age, education, and risk factors on online purchasing behaviour in Malaysia. This study also bridges the gaps in the existing literature and provides information to the owners of online businesses so that they can better understand the determinants of consumer behaviour, which is a challenge due to the non-existence of physical interaction during transactions (i.e., virtual transactions).

\section{Literature Review}

\subsection{SOR (Stimulus-Organism-Response) Model}

This study referred to the SOR model, which comprises three elements: stimuli, organisms, and responses. This model assumes that an organism responds accordingly when exposed to external stimuli [8]. The model theorised that when people are exposed to external stimuli, their 'inner organism changes' precede their behavioural responses. The SOR framework has been adopted in consumer behavioural literature and it is also widely employed in marketing studies (see $[9,10])$. In the context of purchase behaviour, it could be propounded under the premise of SOR framework that the shopping environment contains stimuli that could influence the organisms (consumers) to approach or avoid a store [10]. The consumers under the SOR paradigm are perceived as 'organismic' machines which are presumed to react automatically towards stimuli [9]. In relation to adapting the SOR for the present study, the perceived risks associated with online purchase are considered as the "stimuli", the consumers' age and level of education as the dimensions of "organism", and the influence of online purchasing as the "response".

\subsection{Overview of Online Shopping Context in Malaysia}

In 2015, the Malaysian Communication and Multimedia Commission (MCMC) reported the total number of Internet users in Malaysia, which was 20.6 million [11]. The same report also highlighted that among online shoppers, $44.5 \%$ were 20 to 29 years old and $28.2 \%$ were 30 to 39 years old [11]. These statistics provide an insight into the development of e-commerce in Malaysia, specifically the online purchasing behaviour among the younger generations. Customers used the Internet to search for information such as product prices and ended up purchasing products at the brick-and-mortar stores. This phenomenon occurs due to the customers' concerns about online shopping. Several studies have highlighted the effects of perceived risk in regard to customers' online purchasing behaviour [12,13]. Malaysian online consumers are concerned about seven types of risks (financial risk, product performance risk, time or convenience risk, privacy risk, psychological risk, social risk, and delivery risk) in online shopping [13]. The customers have security and privacy concerns, are unable to wait for a long time to receive the item, are fearful of paying extra for delivery costs, have previous experiences of bad service, and have a lack of confidence or skills [11].

\subsection{Customers' Demographics and Online Purchase Behaviour}

In general, the consumer's information is one of the crucial antecedents of purchasing behaviour [7]. Different types of customers with different characteristics are expected to possess 
different behavioural rules and preferences, and customer classification is considered to be an important issue in studying online customer behaviour [5]. Thus, it is important to determine the customers' demographics such as age, gender, and education level when identifying the online buyers (or non-buyers) and their motivation for exploring online stores [5]. According to Pristiwa et al. [3], individual characteristics such as age, gender, and income could influence the Internet users' behaviour. Farhana, Khan, and Noor [14] further confirmed that demographic constructs such as age, education level, and income have moderate impacts on the online buying decisions. A recent study by Rana and Tirtani [15] found that education has a negative relationship with impulse buying. Ghani and Jan [16] revealed that some demographic profile characteristics such as age have a negative association with impulse buying behaviour. The consumers' online purchase behaviour is dependent on their income, education, generational age, and consumption-related values that are relevant to the products before they decide to purchase online [17]. As a result, the following hypotheses are proposed:

Hypothesis 1 (H1). Age has a negative effect on the online purchase behaviour among the online shoppers in Malaysia.

Hypothesis 2 (H2). Level of education has a negative effect on the online purchase behaviour among the online shoppers in Malaysia.

\subsection{Perceived Risk and Online Purchasing Behaviour}

Since the introduction of the Internet, the growth of e-commerce has been incredibly rapid until the tragedy of the dotcom crash in 2000. That event revealed that e-commerce has both risks and benefits which need to be measured and considered [4]. According to Pristiwa et al. [3], perceived risk and trust in online purchasing have different impacts on the purchase intention. Perceived risk is believed to inversely influence the consumers' attitude, which can positively affect the online purchase intentions [18]. Saw, Goh, and Isa [19] found that perceived risk has a significant negative relationship with online purchase intentions. The existing literature shows that the types of risks that are involved in online purchasing decisions include financial risks, product performance risk, convenience risk, time risk, health risk, product quality risk, after-sale risk, delivery risk, social and privacy risk, and psychological risks (see [19-22]. A recent study by Thakur and Srivastava [22] found that financial risk and privacy risk are some of the risks faced by online shoppers. The fear that purchased products or services are in poor condition caused monetary losses as a result of bad purchase decisions. Besides that, customers who paid by credit card felt insecure about the confidentiality of their information [23]. Customers are afraid to shop online due to risks that they might get disappointed or frustrated if the product does not meet their expectations. Time or convenience risk is another risk that hinders customers from online shopping. Arif et al. [13] stated that risk happens when customers purchase a product that requires a long return process. Furthermore, Zheng et al. [24] and Arif et al. [13] defined social risk as the risk faced by online shoppers by evaluating their actions in purchasing a product. The perception can be positive or negative. Besides that, delivery risk occurs when customers face a long delivery process time or the products are damaged during the delivery process $[14,24]$. The after-sale risk includes online retailers' problems, such as online retailers' image and trustworthiness, which are risks after purchasing products online [24,25]. Table 1 summarises the variables of perceived risk which were studied by previous researchers. 
Table 1. The variables of perceived risk in past studies.

\begin{tabular}{lllllllll}
\hline Authors & FR & PPR & TCR & PR & PsyR & SR & DR & ASR \\
\hline Kumar and Bajaj [26] & $\sqrt{ }$ & $\sqrt{ }$ & $\sqrt{ }$ & & & & & \\
Erdil [27] & $\sqrt{ }$ & $\sqrt{ }$ & $\sqrt{ }$ & & $\sqrt{ }$ & $\sqrt{ }$ & & \\
Tanadi et al. [28] & $\sqrt{ }$ & $\sqrt{ }$ & $\sqrt{ }$ & $\sqrt{ }$ & & & & \\
Aghekyan Simonian et al. [29] & & $\sqrt{ }$ & $\sqrt{ }$ & $\sqrt{ }$ & & & & \\
Zhang et al. [30] & $\sqrt{ }$ & $\sqrt{ }$ & $\sqrt{ }$ & & & & & \\
Zheng at al. [24] & $\sqrt{ }$ & $\sqrt{ }$ & $\sqrt{ }$ & $\sqrt{ }$ & & $\sqrt{ }$ & $\sqrt{ }$ & $\sqrt{ }$ \\
Arif et al. [13] & $\sqrt{ }$ & $\sqrt{ }$ & $\sqrt{ }$ & $\sqrt{ }$ & $\sqrt{ }$ & $\sqrt{ }$ & $\sqrt{ }$ & \\
\hline
\end{tabular}

FR: Financial Risk; PPR: Product Performance Risk; TCR: Time/Convenience Risk; PR: Privacy Risk; PsyR: Psychological Risk; DR: Delivery Risk; ASR: After Sale Risk.

Hence, the following hypotheses are proposed:

Hypothesis 3 (H3). After-sale risk has a negative effect on the online purchase behaviour among the online shoppers in Malaysia.

Hypothesis 4 (H4). Delivery risk has a negative effect on the online purchase behaviour among the online shoppers in Malaysia.

Hypothesis 5 (H5). Financial risk has a negative effect on the online purchase behaviour among the online shoppers in Malaysia.

Hypothesis 6 (H6). Privacy risk has a negative effect on the online purchase behaviour among the online shoppers in Malaysia.

Hypothesis 7 (H7). Product performance risk has a negative effect on the online purchase behaviour among the online shoppers in Malaysia.

Hypothesis 8 (H8). Psychological risk has a negative effect on the online purchase behaviour among the online shoppers in Malaysia.

Hypothesis 9 (H9). Social risk has a negative effect on the online purchase behaviour among the online shoppers in Malaysia.

Hypothesis 10 (H10). Time or convenience risk has a negative effect on the online purchase behaviour among the online shoppers in Malaysia.

\section{Methodology}

This study employed a cross-sectional design and a quantitative approach to measure the effect of perceived risk towards online purchasing behaviour. Google Forms was used as a platform to gather the data due to the complimenting features of Google such as Docs Editor. Then, the data were imported into SPSS and PLS for further analysis. Partial least squares structural equation modelling, also known as PLS-SEM, is a variance-based structural equation modelling (SEM) approach. It is employed to analyse hypotheses. This approach enables the researchers to indirectly include latent constructs, which are measured by manifest variables or items [31]. PLS-SEM path modelling that uses SMARTPLS is suitable for conducting confirmatory factor analysis, which is more reliable and valid [32]. 


\subsection{Research Instrument}

The questionnaire for the online survey was designed using simple and unbiased wordings so that the respondents could easily understand the questions. The questionnaire was designed using English and Malay languages to cater to the target respondents from multicultural races. As recommended by Brislin [33], this study used back-to-back translation to provide an accurate and reliable translation and reduce possible translation errors. The items for the questionnaire (English version) were mostly adopted from previous studies (see Table 2) which were proofread by a proofreader. Then, they were translated into Malay by a senior teacher with a qualification in Malay language study. Then, some minor adjustments were made based on the expert's comments. A pilot test was conducted to check the content validity. Table 1 provides the summary of each variable and its sources. A seven-point Likert scale (very strongly disagree, strongly disagree, disagree, neutral, agree, strongly agree, and very strongly agree) was used for all of the variables.

Table 2. List of variables and sources of questions.

\begin{tabular}{ll}
\hline Variable & Sources \\
\hline Financial Risk, Product Performance Risk & Kumar and Bajaj [26] \\
Time or Convenience Risk & Ariff et al. [13], Zhang et al [30], Javadi et al. [34] \\
Privacy Risk & Kumar and Bajaj [26], Ariff et al. [13] \\
Psychological Risk & Kumar and Bajaj [26], Ariff et al. [13] \\
Social Risk & Ariff et al. [13], Zhang et al. [30] \\
Delivery Risk & Ariff et al. [13], Zhang et al. [30], Javadi et al. [34] \\
After-Sale Risk & Zhang et al. [30] \\
Online Purchasing Behaviour & Zhang et al. [30] \\
\hline
\end{tabular}

\subsection{Sample Selection and Data Collection}

The target respondents for this study were online buyers within the age group of 20 to 39 years old who have purchased online at least once in Malaysia. Online consumers aged 20 to 39 years old were selected for this study because this age group is willing to adopt new technologies and members of this age cohort have a high probability of participating in online shopping. The sample was university students who purchased any product online. The sample was selected using convenience sampling. This study uploaded the survey form to various Facebook pages, including the official page of 'Universiti Malaysia Kelantan' (after receiving the university's approval). To increase the visibility, all Facebook users viewing the message were encouraged to share the message and the link in all social platforms as appropriate. This study only managed to obtain data from a total of 330 respondents after presenting the research objectives and explaining the way the study may use the information collected.

\section{Data Analysis Results}

\subsection{Descriptive Analysis}

The demographic characteristics of the 330 respondents, including their age, gender, ethnicity, and occupation are presented in Table 3.

\subsection{Reliability and Validity}

The Cronbach's alpha values for after-sale risk, delivery risk, privacy risk, product performance risk, psychological risk, social risk, time or convenience risk, and online purchasing behaviour were more than 0.7. For financial risk, the Cronbach's alpha value was 0.680. According to the explanation by Hair, Ringle, and Sarstedt [31], this study considered all of the items to be reliable, as the Cronbach's alpha values for most of the indicators were more than 0.7 . Table 4 shows the results for the evaluation of the measurement model. This study used composite reliability (CR) to measure the internal reliability. In measuring the convergent validity, this study employed average variance extracted 
(AVE), Fornell-Larcker criterion, and Heterotrait-Monotrait Ratio (HTMT) to measure the discriminant validity, as suggested by Hair et al. [35].

Table 3. Profile of the Respondents.

\begin{tabular}{|c|c|c|c|c|c|}
\hline & $N$ & $\%$ & & $N$ & $\%$ \\
\hline Age & & & Ethnicity & & \\
\hline 20 years to 29 years old & 307 & 93.0 & Malay & 193 & 58.5 \\
\hline 30 years to 39 years old & 23 & 7 & Chinese & 114 & 34.5 \\
\hline \multirow[t]{2}{*}{ Total } & 330 & 100.0 & Others & 23 & 7 \\
\hline & & & Total & 330 & 100.0 \\
\hline \multicolumn{6}{|l|}{ Occupation } \\
\hline Government Sector & 17 & 5.2 & Gender & & \\
\hline Private Sector & 107 & 32.4 & Male & 109 & 33.0 \\
\hline Self-employed & 18 & 5.5 & Female & 221 & 67.0 \\
\hline Students & 176 & 53.3 & Total & 330 & 100.0 \\
\hline Unemployed & 12 & 3.6 & & & \\
\hline \multirow[t]{2}{*}{ Total } & 330 & 100.0 & Education & & \\
\hline & & & SPM & 43 & 13.0 \\
\hline Gender & & & STPM & 18 & 5.5 \\
\hline Male & 109 & 33.0 & Diploma & 39 & 11.8 \\
\hline Female & 221 & 67.0 & Bachelor's degree & 207 & 62.7 \\
\hline \multirow[t]{3}{*}{ Total } & 330 & 100.0 & Master's degree & 19 & 5.8 \\
\hline & & & Others & 4 & 1.2 \\
\hline & & & Total & 330 & 100 \\
\hline
\end{tabular}

Note: SPM (Malaysian Certificate of Education); STPM (Malaysian Higher School Certificate).

Table 4. Reliability Analysis.

\begin{tabular}{lcccccc}
\hline Variables & Items & CA & DG rho & CR & AVE & VIF \\
\hline After-Sale Risk & 3 & 0.891 & 0.897 & 0.932 & 0.821 & 2.104 \\
Delivery Risk & 3 & 0.892 & 0.894 & 0.933 & 0.823 & 2.006 \\
Financial Risk & 3 & 0.680 & 0.728 & 0.816 & 0.597 & 1.657 \\
Privacy Risk & 4 & 0.945 & 0.946 & 0.960 & 0.858 & 2.078 \\
Product Performance Risk & 4 & 0.850 & 0.854 & 0.899 & 0.690 & 2.320 \\
Psychological Risk & 3 & 0.761 & 0.763 & 0.862 & 0.676 & 2.332 \\
Social Risk & 3 & 0.894 & 0.895 & 0.934 & 0.825 & 2.392 \\
Time or Convenience Risk & 4 & 0.809 & 0.821 & 0.874 & 0.635 & 2.025 \\
Online Purchasing Behaviour & 5 & 0.905 & 0.906 & 0.930 & 0.727 & - \\
\hline
\end{tabular}

CA: Cronbach's Alpha; DG rho: Dillon-Goldstein's rho; CR: Composite Reliability; AVE: Average Variance Extracted; VIF: Variance Inflation Factors.

For the composite reliability, the indicators of this study have different loadings for all items with values higher than 0.7. It is believed that if the indicators' values for composite reliability are higher than 0.7 then they are considered reliable [29]. Convergent validity signifies that a set of indicators represents the same underlying construct, which can be demonstrated through their unidimensionality. Since the average variance extracted (AVE) values for all items were more than 0.5 , it can be said that there was sufficient convergent validity for all items in this study [31] (see Table 4).

Moreover, the indicators are considered reliable if the absolute standardised outer loadings are higher than 0.7. Table 5 shows that all of the items that measure after-sale risk, delivery risk, financial risk, privacy risk, product performance risk, psychological risk, social risk, time or convenience risk, and online purchasing behaviour were more than 0.7 . The cross-loading values were below the outer loadings, which suggested good discriminant validity. Experts have noted that the cross-loadings of the indicators should be examined to assess the discriminant validity [31]. The Fornell-Larcker criterion is used to assess the discriminant validity at the construct level. The Fornell-Larcker criterion in Table 4 could not detect any lack of discriminant validity. Furthermore, the Heterotrait-Monotrait Ratio (HTMT) is an estimate of the correlation between the constructs, which is parallel with the disattenuated construct score creation. By referring to the value of 0.9 as the threshold, this study concluded that there was no evidence for the lack of discriminant validity and all of the constructs fulfilled the criteria. 
Table 5. Outer model loading and cross-loading.

\begin{tabular}{|c|c|c|c|c|c|c|c|c|c|}
\hline & ASR & DER & FIR & PRR & PPR & PSR & SOR & TCR & OPB \\
\hline ASR-1 & 0.894 & 0.535 & 0.322 & 0.567 & 0.481 & 0.401 & 0.406 & 0.514 & -0.486 \\
\hline ASR-2 & 0.910 & 0.571 & 0.354 & 0.534 & 0.527 & 0.422 & 0.428 & 0.480 & -0.522 \\
\hline ASR-3 & 0.915 & 0.565 & 0.278 & 0.525 & 0.474 & 0.424 & 0.398 & 0.486 & -0.574 \\
\hline DER-1 & 0.502 & 0.922 & 0.273 & 0.427 & 0.507 & 0.460 & 0.467 & 0.390 & -0.391 \\
\hline DER-2 & 0.600 & 0.929 & 0.289 & 0.559 & 0.518 & 0.419 & 0.436 & 0.435 & -0.424 \\
\hline DER-3 & 0.569 & 0.869 & 0.213 & 0.463 & 0.514 & 0.467 & 0.390 & 0.327 & -0.391 \\
\hline FIR-1 & 0.210 & 0.213 & 0.785 & 0.256 & 0.248 & 0.333 & 0.455 & 0.273 & -0.285 \\
\hline FIR-2 & 0.305 & 0.266 & 0.700 & 0.454 & 0.320 & 0.218 & 0.341 & 0.394 & -0.274 \\
\hline FIR-3 & 0.293 & 0.204 & 0.828 & 0.394 & 0.281 & 0.427 & 0.474 & 0.412 & -0.463 \\
\hline PRR-1 & 0.440 & 0.485 & 0.399 & 0.781 & 0.497 & 0.372 & 0.436 & 0.446 & -0.424 \\
\hline PRR-2 & 0.434 & 0.401 & 0.379 & 0.830 & 0.469 & 0.288 & 0.291 & 0.475 & -0.398 \\
\hline PRR-3 & 0.536 & 0.430 & 0.397 & 0.857 & 0.478 & 0.383 & 0.307 & 0.570 & -0.403 \\
\hline PRR-4 & 0.562 & 0.456 & 0.402 & 0.853 & 0.464 & 0.446 & 0.399 & 0.553 & -0.475 \\
\hline PPR-1 & 0.491 & 0.554 & 0.355 & 0.560 & 0.928 & 0.511 & 0.380 & 0.479 & -0.486 \\
\hline PPR-2 & 0.519 & 0.568 & 0.349 & 0.555 & 0.955 & 0.508 & 0.406 & 0.510 & -0.507 \\
\hline PPR-3 & 0.486 & 0.471 & 0.306 & 0.460 & 0.910 & 0.484 & 0.381 & 0.431 & -0.457 \\
\hline PPR-4 & 0.519 & 0.499 & 0.324 & 0.547 & 0.911 & 0.537 & 0.448 & 0.512 & -0.502 \\
\hline PSR-1 & 0.392 & 0.429 & 0.358 & 0.432 & 0.470 & 0.775 & 0.473 & 0.519 & -0.519 \\
\hline PSR-2 & 0.302 & 0.362 & 0.356 & 0.280 & 0.415 & 0.840 & 0.606 & 0.341 & -0.412 \\
\hline PSR-3 & 0.421 & 0.415 & 0.370 & 0.382 & 0.464 & 0.850 & 0.635 & 0.370 & -0.498 \\
\hline SOR-1 & 0.430 & 0.469 & 0.497 & 0.433 & 0.399 & 0.648 & 0.904 & 0.508 & -0.524 \\
\hline SOR-2 & 0.401 & 0.418 & 0.509 & 0.398 & 0.416 & 0.606 & 0.915 & 0.439 & -0.499 \\
\hline SOR-3 & 0.402 & 0.406 & 0.504 & 0.352 & 0.376 & 0.632 & 0.906 & 0.410 & -0.501 \\
\hline TCR-1 & 0.429 & 0.289 & 0.262 & 0.489 & 0.435 & 0.371 & 0.340 & 0.725 & -0.340 \\
\hline TCR-2 & 0.329 & 0.272 & 0.359 & 0.428 & 0.334 & 0.442 & 0.420 & 0.823 & -0.437 \\
\hline TCR-3 & 0.362 & 0.315 & 0.430 & 0.466 & 0.366 & 0.381 & 0.362 & 0.815 & -0.418 \\
\hline TCR-4 & 0.596 & 0.457 & 0.429 & 0.579 & 0.527 & 0.419 & 0.454 & 0.821 & -0.491 \\
\hline OPB-1 & -0.586 & -0.535 & -0.334 & -0.508 & -0.547 & -0.529 & -0.500 & -0.537 & 0.782 \\
\hline OPB-2 & -0.480 & -0.335 & -0.422 & -0.461 & -0.500 & -0.525 & -0.541 & -0.446 & 0.856 \\
\hline OPB-3 & -0.524 & -0.391 & -0.372 & -0.433 & -0.444 & -0.467 & -0.433 & -0.458 & 0.892 \\
\hline OPB-4 & -0.470 & -0.346 & -0.421 & -0.404 & -0.382 & -0.489 & -0.454 & -0.422 & 0.873 \\
\hline OPB-5 & v0.409 & -0.255 & -0.431 & -0.367 & -0.351 & -0.478 & -0.443 & -0.403 & 0.855 \\
\hline \multicolumn{10}{|c|}{ Fornell-Larcker Criterion } \\
\hline ASR & 0.906 & & & & & & & & \\
\hline DER & 0.615 & 0.907 & & & & & & & \\
\hline FIR & 0.350 & 0.286 & 0.773 & & & & & & \\
\hline PRR & 0.545 & 0.566 & 0.361 & 0.926 & & & & & \\
\hline PPR & 0.597 & 0.535 & 0.475 & 0.574 & 0.831 & & & & \\
\hline PSR & 0.459 & 0.494 & 0.441 & 0.551 & 0.452 & 0.822 & & & \\
\hline SOR & 0.453 & 0.475 & 0.554 & 0.437 & 0.435 & 0.692 & 0.908 & & \\
\hline TCR & 0.543 & 0.425 & 0.472 & 0.523 & 0.617 & 0.507 & 0.499 & 0.797 & \\
\hline OPB & -0.584 & -0.444 & -0.464 & -0.528 & -0.514 & -0.586 & -0.559 & -0.536 & 0.852 \\
\hline \multicolumn{10}{|c|}{$\begin{array}{l}\text { Heterotrait-Monotrait Ratio } \\
\text { ASR }\end{array}$} \\
\hline DER & 0.688 & & & & & & & & \\
\hline FIR & 0.446 & 0.374 & & & & & & & \\
\hline PRR & 0.594 & 0.616 & 0.451 & & & & & & \\
\hline PPR & 0.684 & 0.611 & 0.619 & 0.639 & & & & & \\
\hline PSR & 0.548 & 0.595 & 0.577 & 0.644 & 0.546 & & & & \\
\hline SOR & 0.507 & 0.531 & 0.695 & 0.474 & 0.494 & 0.841 & & & \\
\hline TCR & 0.635 & 0.491 & 0.613 & 0.595 & 0.741 & 0.634 & 0.580 & & \\
\hline OPB & 0.643 & 0.486 & 0.556 & 0.564 & 0.578 & 0.694 & 0.618 & 0.614 & \\
\hline
\end{tabular}

Note: (1) ASR: After-Sale Risk; DER: Delivery Risk; FIR: Financial Risk; PRR: Privacy Risk; PPR: Product Performance Risk; PSR: Psychological Risk; SOR: Social Risk; TCR: Time or Convenience Risk; OPB: Online Purchasing Behaviour. (2) The Italic values in the matrix above are the item loadings and others are cross-loadings.

\subsection{Path Coefficients}

Path coefficients can be used to estimate the path relationships in the structural model between the constructs of the model. Table 5 shows that the path coefficients between age, after-sale risk, financial risk, psychological risk, and social risk have a negative and statistically significant effect on the online purchase behaviour at the chosen $5 \%$ level of significance. On the other hand, education, privacy risk, product performance risk, and time or convenience risk have a negative and insignificant effect on the online purchase behaviour at the chosen $5 \%$ level of significance. The delivery risk has a positive 
and insignificant effect on the online purchase behaviour in Malaysia. Regarding the effect sizes $\left(f^{2}\right)$ in Table 6, it was found that age, after-sale risk, privacy risk, and psychological risk have small to medium effects on the online purchase behaviour. Education, product performance risk, delivery risk, and time or convenient risk have almost no effect on the online purchase behaviour, while financial risk and social have zero to small effects on the online purchase behaviour in Malaysia.

Table 6. Path Coefficient.

\begin{tabular}{lccccc}
\hline & Coefficient & $\boldsymbol{t}$-Value & $\boldsymbol{p}$-Value & $\boldsymbol{f}^{\mathbf{2}}$ & Decision \\
\hline Age $\rightarrow$ OPB & -0.163 & 3.995 & 0.000 & 0.056 & Accept \\
Education $\rightarrow$ OPB & -0.026 & 0.683 & 0.247 & 0.001 & Reject \\
After-Sale Risk $\rightarrow$ OPB & -0.299 & 5.141 & 0.000 & 0.095 & Accept \\
Delivery Risk $\rightarrow$ OPB & 0.068 & 1.024 & 0.153 & 0.005 & Reject \\
Financial Risk $\rightarrow$ OPB & -0.101 & 2.057 & 0.020 & 0.014 & Accept \\
Privacy Risk $\rightarrow$ OPB & -0.161 & 1.591 & 0.056 & 0.028 & Reject \\
Product Performance Risk $\rightarrow$ OPB & -0.049 & 0.788 & 0.215 & 0.002 & Reject \\
Psychological Risk $\rightarrow$ OPB & -0.198 & 3.069 & 0.001 & 0.038 & Accept \\
Social Risk $\rightarrow$ OPB & -0.130 & 2.011 & 0.022 & 0.016 & Accept \\
Time or Convenience Risk $\rightarrow$ OPB & -0.080 & 1.478 & 0.070 & 0.007 & Reject \\
\hline
\end{tabular}

OPB: Online Purchasing Behaviour.

\section{Discussion}

In order to extend the existing literature and enable online businesses to forecast consumers' purchasing behaviour, this study examined the effect of age, education, and perceived risk factors on the online purchasing behaviour in Malaysia. The findings revealed that the age of consumers has a negative and significant effect on the purchase behaviour online, which confirmed hypothesis one (H1). This finding is in agreement with the existing literature (see $[3,14,17])$ indicating that consumers' demographics are significant predictors of their online behaviour. For hypothesis two (H2), this study found no significant effect of consumers' level of education on their online purchase behaviour. It is believed that the user-friendly designs and local language used by most online business platforms allowed the consumers, regardless of their education level, to access and purchase online products.

For the perceived risk factors, this study's findings are in line with previous studies (see [19,20,36]), indicating that various risks associated with online transactions are significant determinants of the consumers' online purchasing behaviour in Malaysia. Specifically, after-sale risk has a significant negative effect on the online purchase behaviour, which confirmed hypothesis three (H3). The result of this study is consistent with Zhang et al. [30] regarding online shoppers' fear of the post-purchase phase, Where the customers are often concerned about product warrant after purchasing products online. For hypothesis four (H4), this study found no significant effect of delivery risk on online purchase behaviour. In the case of hypothesis five (H5), this study found a significant negative effect of financial risks on online purchase behaviour. The finding that financial risk is feared by Malaysians is supported by Arif et al. [13]. Malaysian shoppers are concerned about the overcharge of delivery fees. Dhanapal et al. [12] conducted a study on perceived risk and found that Malaysian online shoppers feared financial risks when shopping online.

For hypotheses six (H6) and seven $(\mathrm{H} 7)$, the data did not allow us to conclude that privacy and product performance risk have significant influence on online purchase behaviour in Malaysia. The physiological and social dimensions of perceived risk factors have a significant negative effect on the online purchase behaviour, which confirmed hypotheses eight (H8) and nine (H9). The finding supports a previous study that claimed online consumers are concerned that their purchase might result in dissatisfaction or mental stress, such as loss of self-image and self-concept [26]. Customers who shop online might be influenced by considering individual values regarding the possibility of losing friendship(s), respect, and self-esteem when performing online shopping [34,36]. For hypothesis (H10), this study failed to establish any significant association between time or convenience risk with the online purchase behaviour in Malaysia. 


\section{Conclusions}

The e-commerce in Malaysia is still evolving and it is important to address factors that could influence online shopping behaviours [2]. Moreover, this study was motivated to examine the significant antecedents of online purchase behaviour in Malaysia due to the difficulty of online businesses in decoding their virtual consumers' behaviour as a result of the lack of physical interactions during transactions. Although there were several previous studies that examined the determinants of online purchasing from the perspective of developed countries, there were few studies done that considered the different dimensions of perceived risk in the context of emerging economies, such as in Malaysia. Thus, this study could contribute to the existing body of knowledge by enriching the information about the different types of risk in the Malaysian context.

This study contributed to the SOR framework by examining the determinants of online purchase behaviour under its premise and extending its scope and applicability. In terms of practical implications, the insights of the focused areas from this study could support policymakers and online businesses by enabling them to concentrate on appropriate age groups and formulate policies and programmes that could reduce the different types of risks associated with online transactions. It is hoped that this study can help encourage and enhance online consumerism. Moreover, the researchers intended to contribute new ideas and knowledge to online consumers. This study might promote awareness on perceived risks when shopping online and the impacts of perceived risks. Furthermore, the findings can provide ideas for consumers to reduce their risks perception when shopping online.

In terms of limitations, it is acknowledged that we could not accommodate all the potentially relevant demographic variables that could have some degree of influence over the online purchase behaviour (for example, income level) in the present model. It is recommended that future researchers should extend the present model by integrating other relevant constructs. It could also be worthwhile for future work to extend the findings through cross-country studies in order to better understand the motivators of online purchases and national differences in virtual economy.

Author Contributions: Lead author N.C.N., who was also the lead researcher of the research grant that was received, prepared the research proposal, managed the research project, designed the questionnaire, analyzed the data, and wrote this paper. A.A.M, N.H.B.H and M.N.b.M. contributed to the development of the research model, the literature review, the sample selection, the data collection, and the preparation of the manuscript.

Funding: This research received no external funding.

Acknowledgments: This study was funded by the RMIC, Universiti Malaysia Kelantan, Malaysia, under the grant titled 'Short Term Research Grant (SGJP)'. Project title: Effect of Online Store Image on Perceived Risks Towards Online Purchasing Behavior. Total grant: RM5000.00 (Ringgit Malaysia).

Conflicts of Interest: The authors declare no conflict of interest.

\section{References}

1. Liu, W.; Ji, R. Examining the Role of Online Reviews in Chinese Online Group Buying Context: The Moderating Effect of Promotional Marketing. Soc. Sci. 2018, 7, 141. [CrossRef]

2. Lim, Y.J.; Osman, A.; Salahuddin, S.N.; Romle, A.R.; Abdullah, S. Factors influencing online shopping behavior: The mediating role of purchase intention. Procedia Econ. Financ. 2016, 35, 401-410. [CrossRef]

3. Pristiwa, N.; Huang, W.T.; Ayuningtyas, D. The effect of internet user behavior on effective marketing via online group buying in Taiwan. Proc. AICS Soc. Sci. 2017, 7, 326-333.

4. Sin, S.S.; Nor, K.M.; Al-Agaga, A.M. Factors Affecting Malaysian young consumers' online purchase intention in social media websites. Procedia Soc. Behav. Sci. 2012, 40, 326-333. [CrossRef]

5. Tang, L.; Wang, A.; Xu, Z.; Li, J. Online-Purchasing Behavior Forecasting with a Firefly Algorithm-based SVM Model Considering Shopping Cart Use. Eurasia J. Math. Sci. Technol. Educ. 2017, 13, 7967-7983. [CrossRef]

6. Roy, G.; Datta, B.; Mukherjee, S. Role of electronic word-of-mouth content and valence in influencing online purchase behavior. J. Mark. Commun. 2018. [CrossRef] 
7. Rahman, M.S.; Mannan, M. Consumer online purchase behavior of local fashion clothing brands: Information adoption, e-WOM, online brand familiarity and online brand experience. J. Fash. Mark. Manag. Int. J. 2018, 22, 404-419. [CrossRef]

8. Moon, M.A.; Javaid, B.; Kiran, M.; Awan, H.M.; Farooq, A. Consumer perceptions of counterfeit clothing and apparel products attributes. Mark. Intell. Plan. 2018, 36, 794-808. [CrossRef]

9. Kawaf, F.; Tagg, S. Online shopping environments in fashion shopping: An SOR based review. Mark. Rev. 2012, 12, 161-180. [CrossRef]

10. Peng, C.; Kim, Y.G. Application of the stimuli-organism-response (SOR) framework to online shopping behavior. J. Internet Commer. 2014, 13, 159-176. [CrossRef]

11. Malaysian Communication and Multimedia Commission. Internet User Survey 2016; Malaysian Communications and Multimedia Commission: Putrajaya, Malaysia, 2017.

12. Dhanapal, S.; Vashu, D.; Subramaniam, T. Perceptions on the challenges of online purchasing: A study from "baby boomers", generation " $X$ " and generation " $Y$ " point of views. Contad. Y Adm. 2015, 60, 107-132.

13. Ariff, M.S.M.; Sylvester, M.; Zakuan, N.; Ismail, K.; Ali, K.M. Consumer perceived risk, attitude and online shopping behaviour: Empirical evidence from Malaysia. In Proceedings of the 2014 International Conference on Manufacturing, Optimization, Industrial and Material Engineering, Jakarta, Indonesia, 29-31 March 2014.

14. Farhana, N.; Khan, T.; Noor, S. Factors Affecting the Attitude Towards Online Shopping: An Empirical Study on Urban Youth in Bangladesh. Aust. Acad. Bus. Econ. Rev. 2017, 3, 224-234.

15. Rana, S.; Tirtani, J. Effect of Education, Income and Gender on Impulsive Buying Among Indian Consumer an Empirical Study of Readymade Garment Customer. Eur. J. Bus. Manag. 2015, 7, 96-105. [CrossRef]

16. Ghani, U.; Jan, F.A. An Exploratory Study of impulse buying of Urban Consumers in Peshawar. In Proceedings of the International Conference on business and Economics Research, Kuala Lumpur, Malaysia, 26-28 November 2010.

17. Punj, G. Effect of consumer beliefs on online purchase behavior: The influence of demographic characteristics and consumption values. J. Interact. Mark. 2011, 25, 134-144. [CrossRef]

18. Bianchi, C.; Andrews, L. Risk, trust, and consumer online purchasing behaviour: A Chilean perspective. Int. Mark. Rev. 2012, 29, 253-275. [CrossRef]

19. Saw, S.L.; Goh, Y.N.; Isa, S.M. Exploring consumers' intention toward online hotel reservations: Insights from Malaysia. Probl. Perspect. Manag. 2015, 13, 249-257.

20. Masoud, E.Y. The effect of perceived risk on online shopping in Jordan. Eur. J. Bus. Manag. 2013, 5, 76-87.

21. Orubu, O.F. The impact of perceived risk on willingness to buy in online markets. E3 J. Bus. Manag. Econ. 2016, 7, 13-18. [CrossRef]

22. Thakur, R.; Srivastava, M. A study on the impact of consumer risk perception and innovativeness on online shopping in India. Int. J. Retail Distrib. Manag. 2015, 43, 148-166. [CrossRef]

23. Hong, I.B.; Cha, H.S. The mediating role of consumer trust in an online merchant in predicting purchase intention. Int. J. Inf. Manag. 2013, 33, 927-939. [CrossRef]

24. Zheng, L.; Favier, M.; Huang, P.; Coat, F. Chinese consumer perceived risk and risk relievers in e-shopping for clothing. J. Electron. Commer. Res. 2012, 13, 255-274.

25. Subramanian, N.; Gunasekaran, A.; Yu, J.; Cheng, J.; Ning, K. Customer satisfaction and competitiveness in the Chinese E-retailing: Structural equation modeling (SEM) approach to identify the role of quality factors. Expert Syst. Appl. 2014, 41, 69-80. [CrossRef]

26. Kumar, P.; Bajaj, R. Dimensions of perceived risk among students of high educational institutes towards online shopping in Punjab. J. Internet Bank. Commer. 2016, 21, 1-21.

27. Erdil, S.D. Effects of customer brand perceptions on store image and purchase intention: An application in apparel clothing. Procedia Soc. Behav. Sci. 2015, 207, 196-205. [CrossRef]

28. Tanadi, T.; Samadi, B.; Gharleghi, B. The Impact of Perceived Risks and Perceived Benefits to Improve an Online Intention among Generation-Y in Malaysia. Asian Soc. Sci. 2015, 11, 226-238. [CrossRef]

29. Aghekyan-Simonian, M.; Forsythe, S.; Kwon, W.S.; Chattaraman, V. The role of product brand image and online store image on perceived risks and online purchase intentions for apparel. J. Retail. Consum. Serv. 2012, 19, 325-331. [CrossRef]

30. Zhang, L.; Tan, W.; Xu, Y.; Tan, G. Dimensions of consumers' perceived risk and their influences on online consumers' purchasing behavior. Commun. Inf. Sci. Manag. Eng. 2012, 2, 8-14. 
31. Hair, J.F.; Ringle, C.M.; Sarstedt, M. Partial least squares structural equation modeling: Rigorous applications, better results and higher acceptance. Long Range Plan. 2013, 46, 1-12. [CrossRef]

32. Afthanorhan, W.M.A.W. A Comparison of Partial Least Square Structural Equation Modeling (PLS-SEM) and Covariance Based Structural Equation Modeling (CB-SEM) for Confirmatory Factor Analysis. Int. J. Eng. Sci. Innov. Technol. 2013, 2, 198-205.

33. Brislin, R.W. Back-Translation for Cross-Cultural Research. J. Cross-Cult. Psychol. 1970, 1, 185-216. [CrossRef]

34. Javadi, M.H.M.; Dolatabadi, H.R.; Nourbakhsh, M.; Poursaeedi, A.; Asadollahi, A.R. An analysis of factors affecting on online shopping behavior of consumers. Int. J. Mark. Stud. 2012, 4, 81-89.

35. Hair, J.F.; Ringle, C.M.; Sarstedt, M. PLS-SEM: Indeed a silver bullet. J. Mark. Theory Pract. 2011, 19, $139-152$. [CrossRef]

36. Vernuccio, M.; Pagani, M.; Barbarossa, C.; Pastore, A. Antecedents of brand love in online network-based communities. A social identity perspective. J. Prod. Brand Manag. 2015, 24, 706-719. [CrossRef]

(C) 2019 by the authors. Licensee MDPI, Basel, Switzerland. This article is an open access article distributed under the terms and conditions of the Creative Commons Attribution (CC BY) license (http://creativecommons.org/licenses/by/4.0/). 